\title{
ANÁLISE DO IMPACTO DAS POLÍTICAS PÚBLICAS DE ESPORTES E LAZER EM PETRÓPOLIS
}

Recebido em: 07/07/2014

Aceito em: 02/03/2015

\author{
Renato Farjalla ${ }^{1}$ \\ Universidade de Trás os Montes e Alto Douro (UTAD) \\ Vila Real - Portugal
}

RESUMO : Analisamos o Programa de Iniciação ao Desporto (PID) de Petrópolis, RJ, política pública de atividades esportivas para crianças no contraturno escolar. Este programa não possui ferramenta de avaliação de impacto, analisamos o impacto. Os resultados obtidos apontam para o êxito destas ações, os diretores responsáveis acreditam que os projetos contribuem para a disciplina $(92,4 \%)$, respeito aos professores $(78,9 \%)$, cooperação $(100 \%)$ e desenvolvimento dos alunos $(100 \%)$. Os professores apontam que as atividades do projeto são capazes de desenvolver responsabilidade $(52,2 \%)$, apontam para melhorias na aprendizagem dos alunos $(57,7 \%)$ e acreditam que a prática esportiva melhora os alunos $(100 \%)$. Os pais de alunos apontam mais ânimo para frequentar a escola $(67,7)$, diagnosticando seu caráter assistencialista. Apontamos a falta de clareza na formulação, implantação e controle do programa.

PALAVRAS CHAVE: Avaliação. Políticas Públicas. Esportes. Atividades de Lazer.

\section{ANALYSIS OF THE IMPACT OF PETROPOLIS 'S PUBLIC POLICY IN SPORTS AND LEISURE}

ABSTRACT: We analyzed the Program Initiation Sport (PID) of Petrópolis, RJ, and a public policy for sports activities for children after school. Because this program does not have any social impact assessment tool, we analyzed the impact. The results acquired point to the success of these actions, showing that the headmasters in charge believe that the projects contribute to issues as discipline $(92,4 \%)$, respect to the teachers $(78,9 \%)$, cooperation $(100 \%)$ and students' development $(100 \%)$. The teacher point out that the activities of the project are capable of developing responsibility $(52,2 \%)$, improving learning $(57,7 \%)$ and believe that sport practice improves the students $(100 \%)$. The parents point out an increase in their attitude for attending school $(67,79 \%)$ diagnosing their welfare character. We also pointed out the lack of clarity in the formulation, implementation and control of the program.

KEYWORDS: Evaluation. Public Policies. Leisure Activities. Sports.

\footnotetext{
${ }^{1}$ Doutorando em Desporto da Utad - Portugal.
} 


\section{Contexto da Cidade de Petrópolis}

A cidade de Petrópolis RJ, vivenciou pela primeira vez uma expressiva modificação quanto ao desenvolvimento dos primeiros gestos da administração pública na direção, elaboração e implantação das Políticas municipais de Esportes e Lazer.

Com objetivo de iniciar um processo de ampliação de acesso ao Lazer, Esportes e atividades nas escolas, em contraturno escolar, desenvolveram-se diversos projetos e programas esportivos voltados ao atendimento de uma população menos favorecida residente em Petrópolis/RJ.

A cidadania e a melhoria das condições da Educação - oferecidas através de práticas de Esportes e Lazer - seriam, segundo a visão governamental, uma grandiosa contribuição para minimizar as desigualdades sociais e prevenir outras questões relacionadas direta ou indiretamente às injustiças sociais.

Ressalta-se que a análise e a avaliação de Programas e Projetos Sociais que observem fatores que interferem no desenvolvimento integral da promoção da saúde e da qualidade de vida da população foram apontados por Nahas (2005 p.35): ao demonstrar a dificuldade de se avaliar tais programas de maneira mais efetiva, não apenas de forma eficaz e eficiente. Ao que menciona o autor, que, nos dias de hoje, procura-se por programas efetivos, bem estruturados, com planejamento de recursos financeiros e capital humano adequado, além de tempo suficiente para a sua implantação e coleta de resultados. Evidente que estes programas promoverão o desenvolvimento humano, principalmente as crianças em idade escolar, incentivando uma mudança de comportamento. Ao que parece, contudo, não se disponibiliza além do tempo e dos recursos financeiros, as condições estruturais ideais para realizar tais 
programas sociais. Deste modo, resta realizar estes programas a baixos custos, replicálos e disseminá-los da forma mais simples o possível.

Partindo-se destas considerações limitadoras, podemos indicar a real necessidade de adequar as Políticas Públicas de Educação Física, Esportes e Lazer, além de implantá-las com a melhor qualidade possível dentro das condições impostas pela administração pública do município de Petrópolis/RJ, de modo que atendam minimamente aos grupos sociais para as quais se destinam.

O objetivo geral deste trabalho seria, analisar o impacto proporcionado pelo desenvolvimento de Programas Públicos em Educação Física para crianças em idade escolar, promovidos pela Prefeitura Municipal de Petrópolis, considerando-se suas limitações estruturais e organizacionais, mas, contudo, garantindo, mesmo assim, indicadores de eficiência, eficácia e efetividade para que modificações se façam realizáveis - quando e se necessário. Além de oferecer indicadores de eficiência, eficácia e efetividade para possíveis modificações nestes projetos, bem como avaliá-los perante a comunidade de jovens e crianças nas escolas de Petrópolis.

Como justificativa, acredita-se que este estudo possa viabilizar procedimentos inovadores para análise e desenvolvimento das Políticas Públicas citadas, viabilizando metodologias mais adequadas para avaliar projetos desta natureza e que envolvam somas elevadas de recursos.

A relevância deste trabalho se encontra no fato de que nunca nesta cidade (Petrópolis/RJ) se realizou estudos neste sentido, bem como também não é comum no Brasil este tipo de investigação em Programas Públicos de Esportes e Lazer. Para iniciarmos nosso entendimento seria indicado procurar entender melhor as relações entre o Esporte e a Escola. 


\section{O Esporte e o Esporte nas Escolas}

Na opinião de Lima (1988 p.46): O desporto escolar, entendido e organizado como atividade não curricular, deve ser orientado de forma a não reproduzir os aspectos de alienação dos valores humanos inerentes à criação do desporto e afirmar-se como atividade particularmente favorável à satisfação dos interesses e necessidades relacionais sentidos pelo indivíduo no mundo contemporâneo. O Esporte se descaracteriza à medida que é usado como moeda social na implementação de projetos ou propostas no espaço privado ou público, onde a palavra de ordem não é a sua valorização e sim um eixo para atender aos interesses individuais de forma abusiva, extrapolando o poder econômico, ou ainda, como tráfico de influências para promover as necessidades pecuniárias de quem dele se utiliza.

O Esporte pode ser compreendido como uma atividade plural, com dimensões morais, culturais e educativas, com um padrão de comportamento diferente. O direito a uma prática esportiva é antes de tudo direito, e satisfação daquele que o pratica. Poderíamos então considerar um praticante, simplesmente a criança que o faz, sem sujeitar-se a padrões propostos por qualquer organismo.

Já Betti (1991 p.29): conceitua Esporte como uma ação social institucionalizada, composta por regras, que se desenvolve com base lúdica. Os resultados alcançados pelos praticantes são resultados das habilidades ou estratégias utilizadas por esses, e podem ser intrínseca ou extrinsecamente gratificantes.

O Esporte é um dos mais importantes fenômenos sócio culturais de nossa época, pode ser considerado até reserva social em momentos de crise, é uma verdadeira e poderosa ferramenta de valor humanístico (REIS, 2001, p.14). 
No lado genuíno e positivo, o Esporte serve de instrumento e cenário de divulgação institucional de países, de percuciente formação de imagem externa, de pacificação e congraçamento mundial (VASCONCELLOS, 2008).

A partir da Constituição de 1988 (art.217), o Esporte brasileiro é concebido como atividade de direito de todo cidadão, passa a incorporar de forma plural o exercício deste direito, apoiando-se na Carta Internacional de Educação Física (UNESCO 1978).

Considera-se então o Esporte, segundo Tubino (2006), dividido em: Esporte, Educação, Esporte Escolar, Esporte Lazer e Esporte Rendimento, e ainda demonstra o autor que: No caso do Esporte, para que seja entendido na sua perspectiva do século XXI, terá que ser abordado num processo sócio- cultural- histórico, no qual os aspectos gerais e específicos de suas relações com a sociedade terão que invariavelmente ser referenciados" (TUBINO 2001).

O autor aponta, ainda, abordagens que permitiram formulações de várias perspectivas para o Esporte neste século que se inicia. Entre elas destacamos: "A análise do contexto atual de sociedade como um estudo de tendências, onde destacaríamos a sociedade de massas. [...] se impõe na direção dos planejamentos e Políticas,” (p. 81)

Acrescenta ainda que alterações profundas nas relações entre o Estado, a sociedade, com importância ao respeito, direitos e atendimento às necessidades coletivas.

Demonstrando que um novo paradigma quando o Esporte, a partir da aceitação de que a prática esportiva era um direito de todos, somou a sua perspectiva de rendimento às perspectivas da participação e formações. Estas novas conceituações de Esporte, passaram a contar com as seguintes manifestações, distintas e interatuantes, 
segundo (TUBINO 2001 p.75): A - manifestação do Esporte performance, objetivando rendimento, numa estrutura formal e institucionalizada; manifestação de Esporte participação, visando o bem-estar para todas as pessoas, praticada voluntariamente e com conexões com os movimentos de Educação permanente e com saúde; e a manifestação Esporte Educação, com objetivos claros de formação, norteado por princípios sócio - educativos, preparando seus praticantes para a cidadania e para o Lazer.

Portanto, o Esporte é um fenômeno humano e, por consequência, as tramas que são desencadeadas no universo das relações sociais são caracterizadas em um contexto político vinculado irrefutavelmente ao curso da história. (VARGAS, 2001, p120).

Entende-se, por conseguinte, que os papéis desempenhados pelos atores envolvidos, poderiam ser caracterizados pela emancipação e autonomia, ou pelas relações de dependência e submissão - por consequência, consideraríamos o Esporte como uma forma de entender a realidade.

\section{Uma Breve Trajetória das Políticas Públicas de Esportes e Lazer no Brasil}

Através de revisão para este estudo, encontramos uma constante relação entre Estado e Esporte. Entre 1964 e 1986 o Brasil viveu um período totalitário, que deixou grandes marcas na Educação, seja observado pela antiga Lei de Diretrizes e Bases da Educação Nacional (LDB 5692/71), que condicionava esta disciplina, a Educação Física, apenas como disciplina complementar, coadjuvante do ensino; seja pelo entendimento equivocado que se dava ao Esporte escolar e ao Esporte em tempo livre (Lazer) - por presumir que da escola apenas serviriam os mais habilidosos, referindo-se 
à prática do Esporte escolar como fornecedora de talentos para o Esporte de alto rendimento.

Melo (2005 p.69):

[...] com o golpe militar de 1964, as Políticas de Esporte ganharam outra conotação. Reconhecidas como valiosas na obtenção do controle do consenso popular, os militares buscam apropriar-se das manifestações culturais, entre elas os Esportes. [...] Formula-se a ideia de pirâmide esportiva, na qual se deveriam oferecer oportunidades às massas, com o argumento de que assim surgiriam os grandes talentos esportivos de alto nível. Nesse momento, temos uma grande esportivização da Educação Física. O Esporte passa a ser o conteúdo dominante da Educação Física em detrimento das outras manifestações da cultura corporal.

Ao que se pode entender, a ampliação do acesso ao Esporte é reconhecida pelos militares como direito social. Claro que este reconhecimento se deu em função das possibilidades pedagógicas dos Esportes, bem como sua creditada possibilidade de ocupar o tempo dos jovens com uma diversão sadia.

Um evento histórico é a Campanha do 'Esporte para todos' (EPT), programa de Lazer em 1977, que baseava-se em amplo incentivo às atividades físicas em países europeus. A versão brasileira tinha como incremento a prática de atividades físicas na promoção da saúde. Mas muito diferente do que se proclamava, esta campanha afirmava o ideário militar da época, omitindo questões sociais importantes, direitos civis e utilizando os Esportes como atividades físicas no tempo livre, isto posto os Esportes praticados como Lazer serviriam como instrumento de manipulação do tempo livre do cidadão.

É possível afirmar que nesta versão, esqueceu-se que este tipo de programa era aplicado em países capitalistas centrais, nos quais havia um Estado de bem-estar social que não se deu nos países periféricos. 
Não se pode negar que o movimento EPT produziu alguns resultados no Brasil, entre eles, em opinião pessoal, o início de um processo de visibilidade do Esporte e das atividades físicas.

Ainda se referindo aos Esportes, notadamente ao Esporte praticado nas escolas, considerado como Esporte formal, ministrado dentro das aulas de Educação Física escolar, foi promulgada uma diretriz que propunha um modelo de política pública educacional e apontava para as necessidades da época. O tempo serviu para mostrar as diversas falhas e limitações da Lei no 5692/71 (Lei de Diretrizes e Bases da Educação Nacional - LDB). Sendo assim, adiante, no ano de 1996 foi promulgada a nova Lei de Diretrizes e Bases da Educação Nacional, a LDB nº 93994/96. Em seu parágrafo terceiro, art.26, contempla esta como uma disciplina integrante do currículo escolar, componente da grade regular e que deve ser obrigatoriamente oferecida no ensino fundamental. Além disso, esta lei passa a considerar a prática esportiva como um direito da criança.

Entretanto, no ensino fundamental do Brasil, composto por nove anos, divididos em dois segmentos, do $1^{\circ}$ ao $5^{\circ}$ ano, na grande maioria das escolas públicas, não são oferecidas aulas regulares de Educação Física. Estas apenas são oferecidas a partir do $6^{\circ}$ ano em diante, quando grande parte dos alunos já estão com 12 anos - o que vai de encontro a referências científicas, pois na ausência de atividades físicas e de Lazer durante a primeira fase da infância há substanciais perdas no desenvolvimento motor infantil.

Ao que se pode entender, a ampliação do acesso ao Esporte é reconhecida pelos militares como direito social. Claro que este reconhecimento se deu em função das 
possibilidades pedagógicas dos Esportes, bem como sua creditada possibilidade de ocupar o tempo dos jovens com uma diversão sadia.

Um evento histórico é a Campanha do ‘Esporte para todos' (EPT), programa de Lazer em 1977, que baseava-se em amplo incentivo às atividades físicas em países europeus. A versão brasileira tinha como incremento a prática de atividades físicas na promoção da saúde. Mas muito diferente do que se proclamava, esta campanha afirmava o ideário militar da época, omitindo questões sociais importantes, direitos civis e utilizando os Esportes como atividades físicas no tempo livre, isto posto os Esportes praticados como Lazer serviriam como instrumento de manipulação do tempo livre do cidadão.

Não se pode negar que o movimento EPT produziu alguns resultados no Brasil, entre eles, em opinião pessoal, o início de um processo de visibilidade do Esporte e das atividades físicas.

Ainda se referindo aos Esportes, notadamente ao Esporte praticado nas escolas, considerado como Esporte formal, ministrado dentro das aulas de Educação Física escolar, foi promulgada uma diretriz que propunha um modelo de política pública educacional e apontava para as necessidades da época. O tempo serviu para mostrar as diversas falhas e limitações da Lei no 5692/71 (Lei de Diretrizes e Bases da Educação Nacional - LDB). Sendo assim, adiante, no ano de 1996 foi promulgada a nova Lei de Diretrizes e Bases da Educação Nacional, a LDB no 93994/96. Em seu parágrafo terceiro, art.26, contempla esta como uma disciplina integrante do currículo escolar, componente da grade regular e que deve ser obrigatoriamente oferecida no ensino fundamental. Além disso, esta lei passa a considerar a prática esportiva como um direito da criança. 
Entretanto, no ensino fundamental do Brasil, composto por nove anos, divididos em dois segmentos, do $1^{\circ}$ ao $5^{\circ}$ ano, na grande maioria das escolas públicas, não são oferecidas aulas regulares de Educação Física. Estas apenas são oferecidas a partir do $6^{\mathrm{o}}$ ano em diante, quando grande parte dos alunos já estão com 12 anos - o que vai de encontro a referências científicas, pois na ausência de atividades físicas e de Lazer durante a primeira fase da infância há substanciais perdas no desenvolvimento motor infantil.

Neste cenário, que se estende até os dias atuais, os Programas Públicos de Esportes e Lazer da cidade de Petrópolis tentavam, entre 2000 e 2008, minimizar a carência da oferta das aulas regulares da Educação formal, oferecendo, no contraturno escolar, atividades desenvolvidas em projetos denominados PID (Programa de Iniciação Desportiva) - objeto desta investigação.

Poderíamos então, em comparação simples, considerar os Programas Públicos deste município como sendo semelhantes aos de um clube esportivo? Que funcionariam dentro do tempo livre dos alunos? Contudo, sem o intuito de promover os aspectos educacionais?

Partindo-se destes pressupostos, o Programa Público deveria preencher adequadamente sua função, se possuísse uma visão correta do Esporte fora da escola, Esporte informal, praticado no tempo livre (Lazer) dos alunos das escolas públicas, uma vez que, entendendo-se o tempo livre, poderíamos perceber o seu significado cultural e educativo. Alguns Autores, importantes na compreensão histórica, poderiam subsidiar o entendimento de Lazer, acrescentando mais à análise anterior de Esportes e Políticas Públicas. 
Já em 1948, Dickert, propunha um Lazer "Esporte para Todos", que é para este autor a proposta ideal de sociabilização, através de atividades competitivas, massificados, sem a exigência do Esporte de alto nível, onde busca-se a satisfação pela interiorização de atividades prazerosas, unindo o Lazer- saúde, com o que a atividade pode proporcionar ao indivíduo. Já para Marcellino (1987), o Lazer é compreendido em seu 'sentido mais amplo', vivenciado no tempo disponível, demonstrando toda a ambivalência do Lazer, onde supõe-se que seja possível controlar o tempo livre dos sujeitos envolvidos e regular sua relação com a cultura em vigor. Contrapondo estes autores, para Marcuse (1971): O Lazer seria uma alienação, uma ilusão de autosatisfação das necessidades do indivíduo, porque estas necessidades são criadas, manipuladas pelas 'forças econômicas de produção e de consumo de massa', também presentes nos Esportes.

Portanto, se a escola é compreendida por apresentar-se como uma instituição socialmente voltada para o serviço à comunidade, capaz de receber projetos em contraturno escolar, os Programas Públicos de Esportes e Lazer deveriam oferecer atividades esportivas de forma equilibrada e colaborativa para formar futuros cidadãos. Estes, de certa forma, deveriam poder, em seu futuro, corresponder em suas intervenções sociais de maneira plena. Devemos pensar e refletir sobre o que realmente se passa dentro destes programas e qual a sua concepção verdadeira.

Ao que parece, deve partir da escola o início da criação de vínculo entre a prática esportiva infantil e a própria escola. Isto em virtude de entendermos que é nesta que se encontra o praticante do futuro. Assim, em atividades de Educação Física na escola se educa para o Lazer, ensinando a usufruir do tempo livre disponível de forma mais consciente, e preparando o futuro cidadão para conviver com a sociedade de 
consumo - que, embora seja capaz de aliená-lo em seu tempo disponível, lhe proporciona a benesse do convívio coletivo. Desta forma, este sujeito será capaz de perceber as nuances de sua realidade, e poderá escolher, em sua prática informal, a que mais lhe convém, além de tornar-se capaz de solicitar e exigir, como direito social, a elaboração de ações do Estado, através de políticas públicas, que contemplem suas necessidades e interesses. A escola fomenta o desenvolvimento pela prática esportiva, educa para o Lazer e o tempo livre, enquanto os governos desenvolvem programas e políticas de acesso e desenvolvimento de estruturas em prol da Educação e do Lazer no tempo livre.

A vista disso, compreende-se como de extrema importância a elaboração de um mecanismo para avaliar as Políticas Públicas na cidade de Petrópolis/RJ. Sendo que, diante do modelo impreciso de atuação Política escolhido para a pasta do Esporte e Lazer nos últimos anos dentro da Prefeitura desta cidade, pretendemos que a realização deste estudo acabe por oferecer sugestões para a administração pública.

A definição do papel de cada ator neste cenário seria, minimamente, o entendimento de uma noção mais apropriada de qualidade nas ações públicas. Assim, seria preciso reequacionar as responsabilidades setoriais, repensando a forma como cada ator deve ocupar não apenas o seu papel na sociedade, mas também um papel de interação para o pleno desenvolvimento de Políticas Públicas de Esportes e Lazer que favoreçam os alunos e a cada cidadão deste município.

A partir desta compreensão, percebemos que as Políticas Públicas e competências levadas a cabo pela administração pública, levantam interrogações em sua coerência teórico-prática, nos critérios de aplicação, nas Políticas nem sempre integradas de desenvolvimento dos Esportes, sejam estes em âmbitos formais ou 
informais. Mostram-se inadequadas como Políticas de governo, e controversas enquanto Políticas de Estado. Logo, na medida em que avançamos nas investigações, percebemos também o quanto poderia ser considerada "secreta" a forma de gestão dos recursos provenientes do erário público, tratando-se, então, de encontrarmos mais uma justificativa pertinente: a tentativa de entender melhor e aprofundar os estudos sobre os indicadores produzidos pela administração pública na área dos Programas Públicos de Esporte.

Como demonstra Steinhilber (2008): seria fundamental que as Políticas Públicas, os Planos e Programas estejam claramente identificados e os recursos públicos alocados de acordo com as reais necessidades sociais e não de projeção pessoal. Continua o mesmo autor apontando para que os Programas de governo sejam da compreensão de todos, transparentes, de tal forma que permitam seu acompanhamento de forma simplificada.

Portanto, encontramos, após investigação mais pormenorizada, um conjunto de preocupações voltadas ao fenômeno da prática esportiva, envolvendo responsabilidades inerentes ao projeto, para melhor compreender e avaliar as ações governamentais existentes.

É nosso propósito, após conhecer as estruturas e ações dos Programas das Políticas Esportivas, compreender sua eficiência e efetividade para criarmos alguns indicadores que nos levem organizar e planejar um programa de Esportes e Lazer estratégico, integrado ao desenvolvimento e à necessidade do público local, ou seja, estudantes da rede pública escolar.

Além das competências gerais dispostas na Lei 9394/1996, das diretrizes da Educação Brasileira, da Constituição da República (1988) quanto ao reconhecimento do 
Esporte como direito, da Carta Internacional de Educação Física (1978), a estrutura e a organização dos municípios diante das leis, buscamos um caminho para além dos dispositivos legais e que conduza o direito à Educação Física.

Consolidar as leis, no caso a LDB, seria uma forma de viabilizar, através de princípios, a organização Política de cada município, sendo que permitiríamos a capacidade de resposta eficaz e eficiente a todas as solicitações ou demandas sociais.

Procurar responder ao relevo regional torna-se fundamental, na medida em que as Prefeituras correspondam, via suas secretarias, aos anseios e necessidades do público, atendendo aos objetivos pretendidos para o desenvolvimento local e municipal.

Por outro lado, deve-se estabelecer princípios estratégicos de atuação do município quanto às suas Políticas de governo (ação programática do governo em determinado tempo), baseadas coerentemente em Políticas de Estado (ação ou programas de referência de atuação do Estado), prevalecendo o planejamento integrado no âmbito do desenvolvimento e tendo como perspectiva não apenas o seu crescimento harmonioso, mas também o cumprimento de leis e o respeito à qualidade de vida das populações em geral.

Qualquer município deve ter como objetivo político no âmbito do Esporte de participação ou de educação, a criação de mais e melhores condições para a prática esportiva, dentro das motivações e necessidades dos participantes, adotando práticas que incrementem o desenvolvimento das Políticas para o setor. É preciso ter uma visão macroscópica do sistema esportivo formal e informal local, pensando, de maneira dinâmica, na interação com cada região específica (no caso, cada projeto realizado em cada escola, e escolas de regiões diferentes dentro do município), para procurar criar melhores condições de acesso às práticas, democratizando-as. Assim, certamente 
teríamos, como já mencionado, como dar efetividade e eficácia às propostas de programas públicos de Esportes e Lazer.

Assim sendo, a escola, seria, então, uma instituição social a serviço do indivíduo e da comunidade, que quando está disposta ao público, deve contribuir para além das atividades físicas, com a continuidade de uma formação integral (ressalve-se que esta deveria incluir aulas formais, regulares de Educação Física). Além disso, a escola ainda deveria proporcionar uma formação equilibrada das crianças e jovens, coerente com o sistema educativo, com as obrigações do Estado. Encontramos em Lima (1988) a referência de que a filosofia da Educação defende os valores socioculturais das atividades corporais, acabando com a dicotomia entre trabalho intelectual e o trabalho manual, entre as atividades intelectuais e as atividades físicas, de modo a dignificar a unidade do ser humano e a reconhecer o alcance educativo-formativo das atividades esportivas.

\section{Algumas Referências aos Estudos dos Papéis do Município e do Estado nas Políticas Públicas Brasileiras}

Nos regimes democráticos, a ciência Política é a atividade dos cidadãos que se ocupam dos assuntos públicos com seu voto ou com sua militância. Política pode ser ainda a orientação ou a atitude de um governo em relação a certos assuntos e problemas de interesse público: Política financeira, Política educacional, Política social.

No Brasil ainda se observa a ausência de estudos que reconstituam os modos como foram concebidas as ações públicas destinadas aos jovens ao longo de todo o século XX, em linhas gerais, as políticas voltadas aos jovens e crianças, foram fortemente determinada pelos problemas de exclusão de jovens da sociedade, facilitando o processo de integração ao mundo adulto, quase sempre ressaltando 
pluralidade de enfoque, as características institucionais e diversidades regionais. Desde os anos de 1950, já se desenvolvem quatro grandes eixos, a saber: a ampliação da Educação e a ampliaçãodo tempo livre; o controle social de setores juvenis, o enfrentamento da pobreza e a prevenção de delitos e a inserção laboral de jovens excluídos.

Em seus primórdios, as Políticas Públicas eram consideradas quase exclusivamente outputs do sistema político, o que justificava o fato de a atenção dos investigadores ter se concentrado inicialmente nos imputs, isto é, nas demandas e articulações de interesse. Dessa forma, antes que a análise de Políticas Públicas fosse reconhecida como uma subárea da ciência Política, os estudos recaíam nos processos de formação de Políticas Públicas, "o que parece refletir o status privilegiado que os processos decisórios sempre desfrutam junto aos profissionais da área” (FARIA 2003).

\begin{abstract}
Segundo Trevisan e Bellen (2008): "no final do século XX, com o aprofundamento da crise do welfarestate, com as convulsões econômicas, sociais e Políticas enfrentadas, principalmente a partir do final da década de 1970, junto com o movimento da nova administração pública, o Estado é fortemente questionado tanto em suas funções quanto na real eficácia de suas ações interventoras na realidade social. Aceitando-se que a compreensão do sucesso e do fracasso das Políticas Públicas é fundamental para o melhor desempenho da administração pública, passa-se a algumas considerações sobre o "Estado em Ação".
\end{abstract}

Nos Estados Unidos, segundo Frey (2000 p.15), as pesquisas em Políticas Públicas começaram a se estabelecer no início dos anos 1950, sob a designação de policy science, enquanto que na Europa, especificamente na Alemanha, a preocupação com campus específicos de Políticas somente toma força a partir do início dos anos 1970. Nesse período a unidade de análise torna-se a própria definição das Políticas Públicas, o que conferiu destaque aos aspectos dinâmicos do policy process e aos distintos atores, estatais e não estatais, geralmente envolvidos. No caso do Brasil, os 
estudos em Políticas Públicas são bem recentes. Nesses estudos dispersos, a ênfase recaiu sobre a análise das estruturas e instituições ou sobre a caracterização dos processos de negociação das Políticas setoriais específicas. (FREY 2000). Complementando esta explanação, Faria (2003 p.29) aponta que:

Há atualmente uma babel de abordagens, teorizações incipientes e vertentes análíticas que buscam dar significação à diversificação dos processos de formação e gestão das Políticas Públicas, considerando um mundo cada vez mais caracterizado pela interdependência assimétrica, incerteza e complexidade das questões.

Assim, para que se possa entender melhor a análise das Políticas, Frey (2000), apresenta algumas categorias que têm conseguido relevância na literatura, com ênfase em policy cycle (ciclo político). Este mesmo autor ainda demonstra que o agir públlico pode ser dividido em fases parciais do processo político-administrativo de resolução de problemas, que correspondem a uma sequência de elementos do processo. Comum a todas as propostas de divisões do ciclo político são as fases de formulação, implementação e do controle dos impactos das Políticas.

Destacaremos a última fase deste ciclo político, a avaliação de Políticas e da correção de ação (evaluation), na qual apreciam os Programas já implementados no que diz respeito aos seus impactos efetivos. Investigam-se os déficits de impacto e os efeitos colaterais indesejados para poder extrair consequências para ações e Programas futuros. Nessa etapa, caso os objetivos do Programa tenham sido atendidos, o ciclo político pode ser suspenso ou chegar ao fim, senão à iniciação de um novo ciclo, isto é, a uma nova fase de percepção e definição de problemas. Com isso, a fase de avaliação é imprescindível para o desenvolvimento e a adaptação contínua das formas e instrumentos de ação pública. (FREY, 2000). 
Para uma concepção apresentada de modelo de ciclo político (policy cicle), um processo de resolução de problemas tem necessariamente uma sequência de fases. Observamos que, na prática, os atores políticos-administrativos dificilmente se fixam a esse contínuo, principalmente em programas políticos mais complexos, se estes forem baseados em processo interativos, cuja dinâmica é movida por reações mútuas dos atores envolvidos.

Desta forma, o policy cicle, pode vir a ser utilizado como um quadro de referências para análise, processual. Para Mello (1999), as análise de Políticas Públicas experimentaram um "boom" na década de 80, impulsionadas que foram pela transição democrática e por três motivos: Em primeiro lugar, durante os anos 1970, a agenda pública se estruturou em torno de questões relativas ao modelo brasileiro de desenvolvimento, onde a discussão limitava-se aos impactos redistributivos da ação governamental e ao tipo de racionalidade que conduzia o projeto de modernização conservadora do regime ditatorial. A essa transformação da agenda segue-se uma redescoberta na agenda de pesquisas das Políticas municipais e descentralização. Em segundo lugar, constatou-se que os obstáculos à consecução de Políticas sociais efetivas continuaram existindo, o que serviu para fortalecer os estudos sobre Política. Em terceiro lugar, a difusão internacional da ideia de reforma do Estado e do aparelho de Estado passou a ser o princípio organizador da agenda pública dos anos 1980-90, o que provocou uma proliferação de estudos de Políticas Públicas. As questões de arranjo institucional ganharam grande centralidade na agenda, ao tomar-se o modo e a qualidade da intervenção pública na economia e na sociedade como objeto de estudo, cria-se por extensão um programa de pesquisa de caráter empírico sobre questões relativas à eficiência de Políticas e Programas. 
A área de Políticas Públicas no Brasil atualmente se caracteriza por uma baixa capacidade de acumulação de conhecimento, com acumulação horizontal de estudos de caso e ausência de pesquisa. Ao que parece, esse seria o primeiro problema a ser superado pela área estudada (ARRETCHE, 2003. SOUZA, 2003. MELLO,1999.) .

O discurso sobre política, principalemtne no Brasil, tem recentemente se assumido explicitamente e intencionalmente, ainda que identifiquemos a preocupação do Estado com a formação de políticas públicas, mas as propostas tem invariavelmente ainda um caráter funcionalista.

A Política Pública não se furta ao imperativo da utilidade social, ou seja, mesmo quando adota uma postura crítica, ela o faz apostando na possibilidade de cursos de ação alternativos. Portanto, há poucas dúvidas quanto ao objeto de análise de Políticas Públicas. A análise do "Estado em ação" tem como objetivo específico o estudo de Programas governamentais, suas condições de emergência, mecanismos de operação e prováveis impactos sobre a ordem social e econômica.(ARRETCHE, 2003; REIS 2003).

A amplitude dos estudos em Políticas Públicas apontam para uma grande ocorrência de estudos setoriais, objetos empíricos e por consequência, grande expansão horizontal e ausência de fortaleciento vertical, poderíamos nos apoiar em Souza (2003), para demonstrar que isso acontece em virtude desta área de estudo envolver, no mínimo, análises sobre a identificação do problema que se transoformará ou não em 'uma Política' (agenda setting), a formulação, a legitimação, gestão, implementação e avaliação da Política. Seria então a multidisciplinaridade a essência desta área.

Outro fator de intervenção, seria a proximidade desta área (Políticas Públicas) da burocracia governamental, o que pode resultar em desenvolvimento de estudos e 
trabalhos normativos ou prescritivos, com grande possibilidade desses órgãos de governo ditarem aspectos fundamentais da agenda de pesquisa. Arretche (2003) aponta que o programa de pesquisas brasileiro apresenta-se fortemente subordinado à agenda Política do país.

Ao examinarmos, em nossa revisão de literatura, as indicações destes autores, observamos a submissão das avaliações dos resultados das Políticas aplicadas ou a atualização das informações sobre os Programas já aplicados. De fato, a subordinação da agenda dos estudos à agenda Política é consideravelmente grande nas Políticas Públicas.

Para Carvalho (2003):

Ao se considerar que o sistema das Políticas Públicas é um processo em fluxo, por associação uma dada Política pública não poderia estruturarse como sequência linear em fase. A abordagem que melhor expressa $o$ quadro real das Políticas Públicas é a que considera um processo contínuo de decisões que, se de um lado pode contribuir para ajustar e melhor adequar as ações ao seu objeto, de outro pode alterar substancialmente uma Política pública.

Pode-se demonstrar, por exemplo, que inexiste um plano estatal eficiente para a política de Esporte no Brasil, embora já tenham sido desenvolvidos diversos documentos, que não conseguiram reunir os diversos atores em torno de um modelo profissional de gestão, sendo geralmente obstruído pelo próprio interesse diversificado dentro do setor (DA COSTA, 2005).

Neste campo político, sugere-se diferenciar o Esporte Educação, o Esporte Ciência e o Esporte Lazer da prática esportiva competitiva. Já as práticas sociais deveriam ser incorporadas a um modelo exclusivo nacional, pensado em consonância com o cenário das práticas esportivas, de modo a ter sentido prático dentro de um 
sistema maior. Ao que parece, o fato de isolarem-se os setores dentro do Esporte faz surgir o impedimento que inviabiliza o funcionamento de todas as potencialidades desta área.

Ainda restam dúvidas sobre os papéis de diversos setores, entre eles o Estado, dentro do quadro das Políticas Esportivas e de Lazer, provavelmente em virtude de atrelarem-se à agenda Política e estudos técnicos que envolvem as Políticas Públicas, mas, evidente que percebemos um afastamento dos papéis das instituições diante dos difíceis quadros circunstanciais, dissolvendo a possibilidade do correto cumprimento das Políticas.

Se sugerirmos a distinção de papéis, o papel do Estado (União) poderia ser o de considerar o Esporte em toda a sua abrangência social, fortalecendo o sentido de promoção da saúde, educação e qualidade de vida das populações, desenvolvendo uma Política de longo alcance. O papel dos Estados da Federação seria implementar Políticas e planos partindo-se de Políticas diagnosticadas de acordo com as realidades locais.

Já os municípios teriam um papel de suma importância, promovendo práticas esportivas comunitárias, com responsabilidade direta nas escolas municipais e em Programas de contato direto com comunidades.

Temos, então, um estudo centrado nas Políticas Públicas, onde Carvalho (2003, p.34) concebe Políticas Públicas como:

Linha de ação coletiva que concretiza direito social declarado e garantido em lei. É mediante as Políticas Públicas que são distribuídos ou redistribuídos bens e serviços sociais, em resposta às demandas da sociedade. Por isso, o direito que as fundamenta é um direito coletivo e não individual. 
Percebemos que o caso do Esporte brasileiro deve ser uma questão de Estado, mas que sempre foi deixado à margem pela História do Brasil, principalmente quando deveria voltar-se à organização e estruturação municipal pautada na geografia local.

O momento é oportuno, pois diante das tensões exercidas pelos setores da sociedade, justifica-se a necessidade de aprimoramento e compreensão dos papéis das instituições, somando-se a necessidade de aferição do desempenho dos Programas.

Façanha e Marinho (2001 p. 46):

A discussão de problemas de avaliação em Programas sociais, deve-se ao fato de que os Programas sociais podem ser reconhecidos como organizações complexas, ante os seus objetivos múltiplos, a descentralização administrativa e de execução e os problemas de coordenação que se encontram aí envolvidos.

Pretendemos investigar até onde os Programas desenvolvidos podem modificar eficazmente estas condições de vida das crianças e até que ponto estas modificações podem ser constatadas como benéficas à população.

Utilizando conceitos de eficiência e eficácia de Tubino (1977), temos a eficiência considerada como: critérios de desempenho interno de uma organização medido através da produtividade da mesma, isto é, em termos de alcance de objetivos, recursos e tempo de execução. E o autor continua afirmando que com este entendimento, partiria para análises mais detalhadas das circunstâncias e ainda , utilizando o conceito de eficácia como um critério de desempenho externo de uma organização, demonstrado pela relação entre a produtividade maior ou menor das organizações e diversos fatores de ordem externa para alcançar seus objetivos

Aos conceitos de eficiência e de eficácia, acrescenta-se o de efetividade, que pode ser explicado pelo prolongamento de tempo proporcionado pela eficácia. 


\title{
Para a Avaliação das Políticas Públicas
}

\begin{abstract}
Ala-Harja e Helgason (2000, p. 21) advertem de início que:
[...] "não existe consenso quanto ao que seja avaliação de Políticas Públicas, pois o conceito admite múltiplas definições, algumas delas contraditórias". Esse fato se explica justamente porque a área de Políticas Públicas é perpassada por uma variedade de disciplinas, instituições e executores, abrangendo diversas questões, necessidades e pessoas.
\end{abstract}

Portanto avaliação em Políticas Públicas seria a avaliação dos resultados de políticas de governo e de Estado, propostas e executadas dentro de um limite de tempo. Outros autores complementam com visões específicas sobre o tema. As Políticas Públicas tornam-se programas quando, por ação de uma autoridade, as condições iniciais para sua implementação se concretizam.

Garcia (2001p.17) define avaliação como:

Avaliação é uma operação na qual é julgado o valor de uma iniciativa organizacional, a partir de um quadro referencial ou padrão comparativo previamente definido. Pode ser considerada, também como a operação de constatar a presença ou a quantidade de um valor desejado nos resultados de uma ação empreendida em obtê-lo, tendo como base um quadro referencial ou critérios de aceitabilidade pretendidos.

O propósito da avaliação seria o de determinar a pertinência e o alcance dos objetivos, a eficiência, efetividade, impacto e sustentabilidade do desenvolvimento. A avaliação portanto, deve proporcionar informação que seja crível e útil para permitir a incorporação da experiência adquirida no processo de tomada de decisão. A avaliação deve ser vista como um mecanismo de melhoria no processo de tomada de decisão, a fim de garantir melhores informações, sobre as quais eles possam fundamentar suas 
decisões e melhor prestar contas sobre as Políticas Públicas (ALA-HARJA e HELGASON, 2000).

O uso da avaliação deve ser orientado para a ação, portanto a prioridade seria a de fornecer informação, entretanto diversas definições falham em definir explicitamente o conceito de valor e o de mérito, por fixarem-se exclusivamente no cumprimento e análise de um plano com seus objetivos, supondo que não só este plano, mas também seus objetivos detêm valor e reconhecimento em si próprios. (THOENING 2000; MOKATE 2002).

As informações contidas em uma estrutura de avaliação seriam de grande utilidade, mas observamos que estas são pouco utilizadas, no caso do setor público, observamos que nenhuma iniciativa é geralmente lançada a fim de observar as reformas condizentes - ao contrário, segundo Thoening (2000 p.11):

Pode-se encontrar um certo ceticismo para com a avaliação, particularmente, entre praticantes bem informados e experientes em reforma da gestão pública, alguns até mesmo expressam uma resistência à avaliação que parece predominar no seu próprio governo.

Poderíamos então sintetizar as definições dos autores: Ala-Harja e Helgason (2000): como ausência de consenso, com múltiplas definições e variedade de disciplinas com o propósito de verificar a eficiência, efetividade, impacto e sustentabilidade; Silva e Costa (2002): as políticas públicas dependem de ações de autoridades para se desenvolverem; Garcia (2001) o valor de uma iniciativa, verificando a quantidade presente deste valor nos resultados empreendidos; para Thoening (2000) e Mokate (2002), as avaliações devem ser direcionadas para a ação, com intuito de oferecer informações 
Ao final deste estudo percebemos que as avaliações são um assunto complexo para diversos autores e estudiosos da área de Políticas Públicas, e também na realidade dos sujeitos, as avaliações foram, de fato, um grande problema para os integrantes dos projetos e também para os gestores e executores, que temiam que as informações fossem utilizadas por membros de diversas áreas, como a imprensa e setores do governo, para deflagrar críticas, assim como no caso de resultados positivos, estas serviriam para campanhas de marketing político e institucional.

As informações oferecidas pela Coordenadoria da Prefeitura Municipal de Petrópolis demonstravam que vinte e cinco mil crianças frequentavam o Programa Público na ocasião das investigações, nos anos de 2005, 2006 e 2007.

\section{Caminhos para a Análise do Impacto}

No âmbito do estudo do Esporte e do Lazer de crianças em idade escolar, a investigação realizada no que concretamente diz respeito ao objeto deste estudo - que é o de analisar o impacto proporcionado pelo desenvolvimento de Programas voltados a crianças de uma cidade brasileira - tenta oferecer uma análise do quadro observado na cidade estudada desde 2002, momento em que partimos para as observações de campo, relatando cada detalhe possível para consubstanciar nosso estudo piloto,

(FARJALLA 2007), e desenvolvermos o estudo principal.

Com este estudo, pretendemos oferecer indicadores de eficiência, eficácia e efetividade para possíveis modificações nos projetos realizados nas comunidades escolares de jovens e crianças das escolas públicas.

A pesquisa se propõe a verificar se estes projetos geraram modificações que possam constatar a positividade do investimento em Programas de Esportes e Lazer, 
além de compreender, sobretudo, a análise de responsabilidades e a interação entre as escolas da rede municipal, a Secretaria de Educação e a Coordenadoria de Esportes e Lazer de Petrópolis.

O enquadramento da investigação justifica-se pela necessidade de desenvolver um setor frágil e pouco dinâmico dentro do cenário onde há o desrespeito às leis que obrigam aulas de Educação Física escolar. A não obediência da Lei de Diretrizes e Bases da Educação Nacional, lei nº 9394/96, já comentada, parece contribuir para a situação de debilidade das práticas ligadas à Educação Física, criando-se, assim, um projeto para solucionar, de forma política e assistencial, a ausência de Políticas melhor estruturadas no setor dos Esportes Escolares (formais) e Lazer (informais) da cidade estudada.

O estudo está restrito a trinta e oito escolas do município, sendo que, deste total, o universo de instituições de ensino é de cento e setenta escolas. Foram pesquisadas escolas da região central da cidade, que receberam o Programa de Incentivo ao Desporto (PID).

A constatação de ausência de avaliações dos Programas Públicos de Esportes e Lazer desenvolvidos no município de Petrópolis/RJ evidencia a clara necessidade de que se desenvolvam metodologias mais complexas para oferecer como recurso a avaliação da eficiência, da eficácia e da efetividade de tais Políticas - principalmente quanto às possibilidades de constatação de modificações culturais (no que se refere à forma de usufruir-se dos bens materiais, equipamentos de Lazer, instalações e entretenimentos), bem como quanto às percepções dos envolvidos e responsáveis na melhoria da qualidade de vida das populações beneficiárias dos programas, quanto ao desempenho escolar, quanto às condições de saúde e à redução do risco social. 
Esta pesquisa qualitativa é uma tentativa de entender os compromissos morais e políticos dentro deste estudo, das experiências com o real, da realidade mutável e instável, do que se vive rotineiramente, sem que, ao mesmo tempo, abra-se mão de uma abordagem positivista.

Para o conhecimento do universo de estudo e localização, utilizamos os endereços que constavam no cadastro da Secretaria de Educação deste município, além de informações da Coordenadoria de Esportes e Lazer. A partir de uma amostra de setenta escolas constatadas na rede municipal, constitui-se este estudo em trinta e oito destas - (um total de $54,2 \%$ ) da população em estudo. Sendo o número de alunos integrantes do projeto que constituem a amostra de sete mil oitocentos e cinco crianças $(31,2 \%)$ da população de 25 mil alunos - segundo a Prefeitura Municipal de Petrópolis (2009).

Foi realizada uma entrevista com cada diretor ou diretora responsável pela instituição e em cada projeto instalado, seja dentro do ambiente escolar, seja nas quadras esportivas das proximidades, houve a preocupação de esclarecer os objetivos propostos por esta investigação. As identidades foram mantidas em sigilo. Em cada escola em que o Programa de Iniciação Desportiva funcionasse, submetemos entre dois a quatro professores das escolas participantes ao instrumento, não sendo estes diretamente professores de Educação Física relacionados ao Programa, mas sim relacionados às turmas que frequentavam o projeto, somando um total de cento e nove professores nas trinta e oito escolas investigadas. Assim sendo, verificamos que as turmas contavam com tamanhos diferenciados: entre quarenta e cinco a quatrocentos alunos.

\section{Os Questionários}


Foi elaborado um instrumento para cada parte integrante desta investigação, para que pudéssemos, assim, avaliar o impacto percebido por cada um dos segmentos envolvidos, sendo: para os professores das escolas, os profissionais envolvidos nos projetos, e os responsáveis ou pais das crianças participantes.

Estes instrumentos foram desenvolvidos da seguinte forma: um questionário fechado para os pais e dois questionários semiestruturados ${ }_{2}$ destinados aos professores das escolas e diretores.

O primeiro instrumento (semiestruturado), destinado aos diretores responsáveis pelas escolas municipais, destinava-se a verificar a estrutura física e organização, aspectos quantitativos relativos ao projeto. O segundo instrumento (fechado), destinado aos pais e responsáveis, destinava-se a verificar se os responsáveis percebiam modificações e alterações no comportamento e desempenho dos alunos e na estrutura dos núcleos esportivos.

O terceiro instrumento (semiestruturado) destinava-se aos professores, averiguando desempenho escolar, comportamento em ambiente escolar e informações não abordadas.

Ao pretendermos assegurar ao presente estudo a qualidade das questões e respostas, optamos por diferentes tipos de validade, nomeadamente a validade de construção e de conteúdo. A primeira validade, que afere a estrutura teórica dos instrumentos, foi balizada por uma objetivada discussão e especulação conceitual, com diferentes especialistas a fim de fidelizar o mínimo de evidência de construtividade.

Já a segunda, tem como objetivo afiançar o instrumento de avaliação, de forma representativa e proporcional, uma tentativa de determinar os objetivos, os temas e os processos envolvidos (perceptivos, cognitivos, intelectuais e sociais). 
Procuramos levar em conta a relevância que adquire a consideração do contexto, a complexidade das interações, a pluralidade e diversidade cultural, as necessidades, as representações, a imprevisibilidade de acontecimentos e a interpretação dos dados obtidos. Desta forma respondemos também a uma variável ecológica.

A análise de conteúdo teve como base um conjunto de indicações de Bardin (1994), calculando-se posteriormente o total de respostas dentro de cada categoria e, desenvolvendo-se a pré-análise através de leitura e transcrição, na íntegra, dos questionários com respostas dadas, codificando-se os dados e transformando-os, por recorte, agregação e enumeração, em representações de conteúdo susceptíveis a esclarecer as características do texto, categorizando os elementos constitutivos, reunidos em grupos de elementos (unidade de registro), em razão dos caracteres comuns destes elementos.

A codificação da análise de conteúdos, unidades de registro e de contexto, e a categorização foram lidas por mais um pesquisador para análise da clareza e compreensão e repartição em categorias e respectivas subdivisões, antes de se proceder ao tratamento estatístico simples com base nas percentagens.

Para as perguntas fechadas de respostas qualitativas a partir de um conjunto de respostas fornecidas por nós, o respondente procurou assinalar as que mais se aproximavam de sua opinião e para as perguntas de respostas quantitativas.

Obtivemos então três questionários que originaram bases distintas:

Questionário destinado aos diretores, possuindo 6 blocos de perguntas, com várias alíneas, possuindo cada uma 6 questões abertas e 9 questões fechadas e mais 6 questões semiabertas. Questionário destinado aos professores: possuindo 6 perguntas, sendo 1 pergunta aberta e 5 perguntas fechadas com vários subitens. Questionário 
destinado aos pais e responsáveis: composto de 5 perguntas com vários subitens, sendo as perguntas fechadas.

\section{Análise dos Resultados}

Para efeito de procedimentos estatísticos selecionamos aleatoriamente dentro deste universo pesquisado, de nove modalidades esportivas, uma amostra possível de ser analisada, não só partindo do que consideramos como variável independente - os trinta e oito núcleos do programa de iniciação ao desporto -, mas também a capacidade de analisar e responder às onze variáveis descritas no quadro acima. Para tanto, para efeito de cálculos selecionamos 4 (quatro) instrumentos respondidos por diretores das escolas contempladas, 4 (quatro) instrumentos respondidos por professores das escolas e 4 (quatro) instrumentos respondidos por pais de alunos, para que a partir desta amostra fossem realizadas análises compatíveis com as possibilidades lógicas necessárias para comprovação deste estudo.

Os dados, ainda sim, mantiveram a proposta inicial de avaliação, oferecendo através da estatística descritiva os resultados gerais, da análise de discurso à resposta para as questões abertas. No que se refere as variáveis independentes consideraremos as seguintes:

Núcleos do Programa de Iniciação ao Desporto;

Quanto às variáveis dependentes, consideraremos as medidas tomadas com base nas respostas obtidas através das questões nos instrumentos aplicados. Estas variáveis foram agrupadas em dimensões, subdimensões, categorias (valores) e subcategorias (itens). 
Assim para os diretores, a dimensão valorização compreende 4 indicadores; a dimensão infraestrutura compreende 14 indicadores, a dimensão colaboração 1 indicador, a dimensão sugestão possui 1 indicador.

Para os Professores: a dimensão valorização compreende 2 indicadores; a dimensão desenvolvimento compreende 3 indicadores, a dimensão atitudes e valores possui 2 indicadores, a dimensão comunicação possui 1 indicador.

Para os pais; a dimensão atitudes e valores compreende 1 indicador, a dimensão desenvolvimento compreende 2 indicadores, a dimensão valorização compreende 3 indicadores; a dimensão comunicação compreende 1 indicador, a dimensão adequação da infraestrutura possui 1 indicador, a dimensão da utilização da infraestrutura possui 1 indicador.

\section{Os Diretores}

Adequação das estruturas destinadas ao desenvolvimento dos projetos, onde com o instrumento utilizado, procuramos averiguar a estrutura física das instalações onde se realizam as atividades do (PID). O quantitativo de alunos observado foi uma maneira de verificarmos se o espaço é saturado ou não. Nos trinta e oito núcleos obtivemos $(205,39$ +116,08) em relação ao número de alunos por núcleo. Em relação às faixas etárias que frequentam as atividades oferecidas obtivemos $(8,96 \pm 1,96)$. Sendo que o tempo médio de oferecimento das atividades nos núcleos foi de $(3,53 \pm 1,29)$, em relação à média de aulas por semana obtivemos $(2,0+1,10)$, as informações quantitativas obtidas informaram apenas um total de quatro mil e dezesseis alunos (4016),

Os itens escolhidos pelos diretores como melhorias percebidas nos alunos: cooperação $100 \%$; sociabilidade $97,3 \%$; disciplina $92,1 \%$; disciplina no tempo livre $52,6 \%$, valores 
$52,6 \%$; concentração $50,3 \%$. Pelos diretores, houve um impacto positivo com o desenvolvimento do projeto.

\section{Os Professores}

Como já comentado, foram inquiridos cento e nove professores das escolas municipais beneficiadas pelo programa público para a realização deste trabalho, tomamos como cautela investigar os professores que não trabalhassem nas atividades esportivas com as crianças envolvidas, e sim nas salas de aula - desta forma, acreditamos colher melhores resultados dos depoimentos destes. Foram cinco questões fechadas e uma questão aberta.

Quando inquirido se observavam melhorias nos alunos frequentadores do projeto, responderam que $\operatorname{sim}(57,70 \%)$ e que não $(42,20 \%)$.

A percepção dos professores quanto a melhorias nos alunos foi sim 57,7\%. Quando perguntados se poderiam apontar os benefícios ou não constatados nestes alunos os professores responderam da seguinte forma. Melhorou muito no relacionamento com familiares e amigos 55,04\%. Apresentou mais ânimo para frequentar a escola 53,21\%. Demonstrou-se mais disposto para a prática esportiva 55,04\%

Os professores demonstraram que quanto ao desempenho escolar as respostas foram as seguintes: As respostas dos professores a percepção de melhoria no desempenho escolar: Sim 52,29\% $(n=109)$. A constatação dos professores quanto às melhorias percebidas: Melhorou as notas escolares 9,17\%. Não houve melhorias que possa perceber40,36\%Mantiveram-se iguais no desempenho36,69\% Não melhoraram seu desempenho1,8\%. As respostas dos professores em relação ao desenvolvimento dos alunos (n=109). Sim 27,52\%. Não 27,52\%; Apenas em algumas 44,95\%. 
Quadro 1: análise das questões abertas:

\begin{tabular}{|c|c|c|c|}
\hline Maiores incidências & $\begin{array}{l}\text { Número de respostas } \\
\text { encontradas }\end{array}$ & $\begin{array}{l}\text { Em relação à amostra } \\
(\mathrm{n}=109)\end{array}$ & Categorias \\
\hline $\begin{array}{l}\text { A prática esportiva } \\
\text { motiva os alunos }\end{array}$ & 100 & $91,7 \%$ & Motivação \\
\hline $\begin{array}{l}\text { Mais } \\
\text { comprometimento } \\
\text { com a escola }\end{array}$ & 40 & $36,69 \%$ & Envolvimento \\
\hline $\begin{array}{l}\text { Alguma felicidade e } \\
\text { esperança em meio à } \\
\text { tanta violência }\end{array}$ & 50 & $45,89 \%$ & Expectativa de futuro \\
\hline $\begin{array}{l}\text { Redução da tensão } \\
\text { social na escola }\end{array}$ & 66 & $60,55 \%$ & Tensão e violência \\
\hline $\begin{array}{l}\text { Mais qualidade nas } \\
\text { ações escolares }\end{array}$ & 40 & 36,69 & $\begin{array}{l}\text { Qualificação das } \\
\text { Políticas Públicas } \\
\text { para escolas }\end{array}$ \\
\hline $\begin{array}{l}\text { Mais qualidade nas } \\
\text { ações do governo }\end{array}$ & 30 & $27,52 \%$ & $\begin{array}{l}\text { Qualificação das } \\
\text { Políticas Públicas }\end{array}$ \\
\hline \multirow[t]{2}{*}{$\begin{array}{l}\text { Melhor } \\
\text { desenvolvimento } \\
\text { motor e cognitivo }\end{array}$} & 60 & $55,04 \%$ & $\begin{array}{l}\text { Desenvolvimento } \\
\text { motor infantil através } \\
\text { das ações públicas }\end{array}$ \\
\hline & & $(50,58+21,40)$ & \\
\hline
\end{tabular}

\section{Os Pais e Responsáveis}

Os instrumentos aplicados obtiveram alcance de quinhentos e trinta e um respondentes, $(\mathrm{n}=531)$, sendo um instrumento fechado, que tinha como finalidade obter dos pais as informações necessárias para analisarmos o contexto.

Na primeira questão, relacionada à percepção dos pais em relação a possíveis melhorias proporcionadas pela participação das crianças no projeto esportivo, obtivemos: 
A percepção dos pais e responsáveis sobre possíveis melhorias nos participantes: Sim 60,26\% Não:39,73\%.

$\mathrm{Na}$ questão em que deveriam assinalar quais as mudanças mais facilmente percebidas, foi permitido que em cada resposta mais de um item fosse assinalado, sendo esta alternativa uma forma fácil de verificarmos a percepção e o envolvimento dos pais e responsáveis com o desenvolvimento do projeto. Assim, as mudanças percebidas pelos pais e responsáveis quanto à participação das crianças foram: Melhorou muito no relacionamento com familiares e amigos 40,48\%, Não melhorou no relacionamento com familiares e amigos $20,71 \%$.

Na questão relativa ao desempenho escolar, se este apresenta mudanças ou não, sem que os responsáveis demonstrassem as notas relativas ao desempenho, tentamos através do instrumento obter a percepção destes sobre o desempenho dos filhos, ao mesmo tempo procuramos estabelecer uma noção de envolvimento dos pais com as atividades desenvolvidas.

As mudanças de desempenho constatadas pelos pais: Pais/responsáveis $(\mathrm{n}=531)$ Sim 42,18\% . Não 57,81\%. A percepção dos responsáveis sobre o desempenho das crianças: Melhorou nas notas escolares 21,28\%. Não melhorou nas notas escolares 19,02\%Não houve melhorias que possa perceber41,99\% Manteve-se igual no desempenho18,83\% Piorou o desempenho $17,77 \%$

As principais mudanças e opiniões dos pais: Frequenta espaços comunitários fora do horário do projeto $89,07 \%$ Aparenta mais ânimo para frequentar a escola $67,79 \%$ Demonstra-se mais disposto para a prática esportiva $54,84 \%$. Melhorou muito no relacionamento com familiares e amigos $40,48 \%$. 
A constatação dos professores quanto às melhorias percebidas: Melhorou as notas escolares $9,17 \%$ Não melhorou as notas escolares $11,92 \%$ Não houve melhorias que possa perceber 40,36\% Mantiveram-se iguais no desempenho 36,69\% Não melhoraram seu desempenho1,8\%.

A perspectiva de uma discussão de resultados num programa de Esportes públicos deveria passar obrigatoriamente pelo oferecimento público de informações relevantes, entretanto não aconteceu desta forma.

\section{Conclusões}

O programa de Iniciação ao Desporto (PID), caracterizou-se, em primeira visão, como um avanço no trato das atividades relacionadas às Políticas Públicas de Esportes e Lazer em Petrópolis - encontramos uma situação de grandes dificuldades sociais, culturais e estruturais, características estas que pressupomos, não devem ser muito diferentes das demais cidades do interior do Brasil. As estruturas débeis, limitadas e o próprio entendimento do papel da escola, do que é um núcleo de Esportes e Lazer, são a consequência e ao mesmo tempo o contínuo de uma realidade de deficiências.

Da análise das estruturas encontramos diversas contradições. Talvez a mais séria seja a diferença entre o que é relatado nos instrumentos aplicados aos diretores e o que é informado pela Secretaria de Esportes e Lazer, responsável em administrar o projeto.

As informações prioritárias, dadas pelos diretores, residiam quase que exclusivamente em dados quantitativos, referentes aos atendimentos, números de crianças, registros de cumprimento de normas - nada mais aprofundado, questionado, no sentido de permitir a reflexão sobre a possibilidade de mudanças para melhor. 
Obtivemos algumas respostas que demonstram impactos positivos em questões como cooperação, sociabilidade, respeito.

Quanto aos professores, suas opiniões ofereceram-nos alguns indícios de melhoria no desempenho dos alunos envolvidos, da preocupação sobre utilização dos equipamentos disponíveis da melhor maneira cabível a este contexto. Acreditamos que por estes, ocorreu uma singela melhoria na utilização dos equipamentos públicos de Lazer: quadras de Esportes, mas não expressivamente significativa na forma de utilização, diante do tamanho da população inserida neste projeto.

Já os pais e responsáveis, perceberam como impacto positivo, ligadas à frequência de utilização dos espações comunitários, a escola, aumento de interesse pela prática esportiva e no relacionamento com familiares

Para a cidade de Petrópolis, seria importante evidenciar, após este estudo, a constatação de que o programa de iniciação ao desporto, enquanto existiu, ofereceu oportunidades de inclusão aos alunos do sistema público através do Esporte e Lazer, com alguma eficácia. Considerando as limitadas possibilidades do programa, mesmo que esta percepção detectada fosse discreta, podemos afirmar que a efetividade das ações desta gestão responsável pelo projeto de iniciação ao Desporto obteve modesto sucesso. No que se pode perceber do quadro destes Programas Públicos é que a definição, a implementação e a avaliação de Políticas para os Esportes e Lazer no contraturno escolar, devem ser precedidas de compreensão das necessidades locais.

Ainda podemos concluir que: as Políticas Públicas, assumem uma determinada direção ideológica na esfera nacional e outra nas esferas estadual e municipal. Estas orientações resultaram em diferentes modelos de gestão pública e, que hoje, parecem conviver em consenso, ou em conflito, direcionado à aplicação dos recursos, à 
concepção e aplicação de Programas e sua avaliação. Contudo, quando nos referimos ao Lazer e ao Esporte, embora constatamos que tais Políticas tenham sido estabelecidas em diferentes períodos da História Política Brasileira como há diferentes concepções, obviamente as concessões orçamentárias, as legislações pertinentes ao setor e o próprio estabelecimento e acompanhamento de Programas seguem critérios que estão pautados mais em acordos políticos - partidários, do que no atendimento a parcelas da sociedade civil que precisariam ter acesso a esses bens (que, em última análise, lhes pertence).

Além disso, salvo algumas iniciativas isoladas, o controle e a avaliação dos Programas são precários. Este acompanhamento deveria ser realizado desde sua implementação, passando pela dotação orçamentária (e as leis que a sustentam) até uma avaliação de impacto social destas Políticas. Outro ponto de fundamental importância, para quem vai se debruçar sobre os estudos de Políticas Públicas de Lazer e de Esporte no Brasil ou mesmo administrá-las é a consciência de que o delineamento teórico que irá sustentar a ação deveria ter papel determinante nas mesmas. Entretanto, o que temos constatado é que há uma lacuna entre o que se escreve e o que se coloca em prática.

Certamente, mudanças substanciais seriam implementadas caso diferentes setores planejassem e efetivassem práticas multidisciplinares nestes e em outros campos. Por fim, poderíamos afirmar que o campo do Lazer e do Esporte ainda carece do desenvolvimento de estudo comparativo sobre os diferentes modelos de gestão, dos investimentos públicos e sua aplicação, dos impactos sociais destas Políticas, da coerência entre discurso e ação, da dimensão da representação individual do Lazer e o impacto que pode ter sobre a construção coletiva destas Políticas.

\section{REFERÊNCIAS}


ALA- HARJA, M. HELGASON, S. Em direção às melhores práticas de avaliação, Revista do Serviço Público, Brasília, v.51, n.4, p. 5-59, 2000.

ARRETCHE, M. Dossiê agenda de pesquisa em políticas públicas. Revista brasileira de ciências Sociais, São Paulo, v.18, n. 51. p.7-9, 2003.

BARDIN, L. Análise de conteúdo. Lisboa: Edições 70, 1994. 221p.

BETTI, M. ZULLIANI, L.R. Educação Física Escolar: Uma proposta de diretrizes pedagógicas. Revista Mackenzie de Educação Física e Esportes, São Paulo, v.1, p73$81,2002$.

BRASIL. Constituição. Constituição da República Federativa do Brasil. Brasília: Senado, 1988.

BRASIL. Senado Federal. Lei de Diretrizes e Bases da Educação Nacional: n5691/71. Brasília: Gráfica Senado, 1971.

BRASIL. Ministério da educação. Lei $\mathrm{n}^{0}$ 9394, 20 de Dezembro de 1996, que 'estabelece as diretrizes e bases da educação nacional', e dá outras providências. Presidência da República-Casa Civil-Subchefia de Assuntos Jurídicos. Disponível em: http://www.planalto.gov.br/ccivil_03/Leis/2003/L10793.htm .Acesso em 10 dez. 2006.

CARVAlHO, S. Análise das Políticas públicas brasileiras. Rio de janeiro: Ed. Cortes, 2002. 98p.

CARVALHO, S, N, Avaliação de Programas Sociais: balanço das experiências e contribuições para o debate. São Paulo em perspectiva, São Paulo, v.17, n. 3-4, p.185197.Jul/Dez 2003.

DACOSTA. Atlas do Esporte brasileiro. Rio de Janeiro: Shape. 2005.

DICKERT, J. Esporte de Lazer. Tarefa e Chance para todos. Rio de Janeiro: Ao Livro Técnico, 1984.

FAÇANHA E MARINHO. Programas Sociais: Efetividade, eficiência e eficácia como dimensões operacionais de avaliação. Rio de Janeiro: (IPEA) Ministério do Planejamento Orçamento e Gestão, 2001.

FARIA, C, A, Ideias Conhecimento e Políticas Públicas: Um inventário Sucinto das Principais vertentes analíticas recentes. Revista Brasileira de Ciências Sociais. São Paulo, v.20, n.59, p.21-29 fev.2003.

FARJAllA, R. - Petrópolis Sports and Leisure Public Policies: Analysys of their impact on the formation of citizenship and the development of the population, 2007

FREY, K. Políticas públicas: um debate conceitual e reflexões referentes à prática da análise de políticas públicas no Brasil. Planejamento e Políticas Públicas, Brasília, n. 21, p. 211-259, 2000. 
GARCIA, R, C, Subsídios para organizar avaliações da Ação Governamental, Planejamento e Políticas Públicas. Brasília, n.23, p. 7-70 Jan/Jul. 2001.

LIMA, T. O desporto está nas Suas Mãos. Lisboa: Livros Horizonte, 1988. p.88.

MARCELlinO, N.C. Políticas Públicas Setoriais de Lazer. Campinas: Autores associados, 1996. p79.

MARCUSE, H. La Agressividad em La Sociedad Industrial Avanzada. Madrid: Aliaza Editorial, 1971.

MELO M.P. Esporte e Juventude pobre: políticas de lazer na vila Olímpica da Maré. Campinas: Autores Associados, 2005. p. 71-81.

MELlO, M, A, As sete vidas da Agenda Pública brasileira. In: Rico E, M (Org.) Avaliação de Políticas Sociais: Uma questão em debate. São Paulo: Cortez, 1999 p.11-29.

MOKATE, K. M. Convertiendo el "Monstruo" em aliado: la evaluacion como herramienta de la gerencia social. Revista do Serviço Público, Brasília, v.53, n.1, p. 89-13,1 Mar 2002.

NAHAS, F. Conferência para a promoção da saúde. SESC. Acesso 10-10-06.2005.

PREFEITURA Municipal de Petrópolis. PID. Programa de Iniciação Desportiva Municipal, 2005.

PREFEITURA MUNICIPAL DE PETRÓPOLIS. Programa de Iniciação ao Desporto, PID. Petrópolis: PMP, 2009. p.1-59.

REIS, E. Reflexões legais para a formatação de uma agenda de pesquisa em Políticas Públicas. Revista Brasileira de Ciências Sociais, São Paulo, v.18. n. 51, 2003, p.1114.

SILVA, P, L, B, COSTA, N, R, Avaliação de Programas Públicos: reflexões sobre a experiência brasileira. Brasília: IPEA 2002.

SOUZA, C. Estado de campo da pesquisa em Políticas Públicas no Brasil. Rev. Brasileira de Ciências Sociais, v.18 p. 51-55, 2003.

STEINHILBER, J. Educação física, Esporte e Escola. In: VARGAS et al. (Org.). Questões do Esporte LECSU, p.61-68, 2008.

THOENING J.C. Avaliação como conhecimento utilizável para reformas de gestão pública. Revista do serviço Social, Brasília, v. 51, n. 2, p.54-70, 2000.

TREVISAN. A. P., BELLEN H. Avaliação de Políticas públicas: uma revisão teórica de um campo em construção. RAP. Revista de Administração Pública FGV, Rio de Janeiro, 2000.

TUBINO, M.J. G. Dimensões Sociais do Esporte. 2. ed. São Paulo: Ed. Cortez,2001. 
TUBINO, M. J. G. Os conceitos de Eficiência e Eficácia como orientadores administrativos de cursos e graduação em Educação Física. Brasília: Ministério da Educação e Cultura, Departamento de Desporto e Educação, 1977.

UNESCO Carta Internacional de Educação Física e do esporte. Paris, 1978.

VARGAS, A. Ética: ensaios sobre educação física social e esporte. Rio de Janeiro: LECSU, 2007. p121

VASCONCELOS, D. W. Esporte Poder e Relações intersetoriais. Brasília: Fundação Alexandre Gusmão 2008.

\section{Endereço do Autor:}

Renato Farjalla

Av. Barão do Rio Branco 1556 - Centro

Petrópolis - RJ - 25600-150

Endereço Eletrônico: renatofarjalla@gmail.com 